\section{Confianza democrática y proceso de formulación de políticas públicas: el caso de la política hídrica de Cataluña}

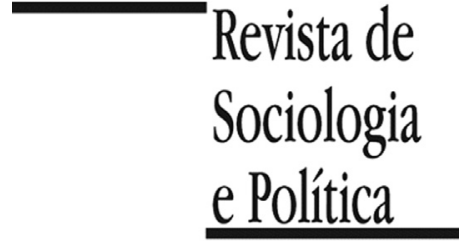

DOI: $10.1590 / 1678987318266707$

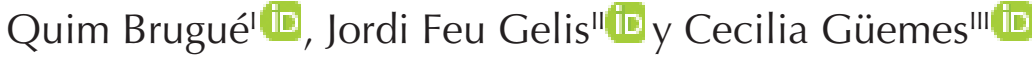

RESUMEN Introducción: Bajo la premisa de que los sistemas político-administrativos democráticos funcionan a través de ciertas asignaciones de confianzas y desconfianzas, este artículo se propone reflexionar sobre una realidad en la que reina una doble desconfianza entre la ciudadanía y las administraciones públicas, con base en la elaboración y posterior aprobación, tras un proceso participativo, de los Planes de Gestión de las Cuencas Internas de Cataluña. Métodos: Tras unos apartados de carácter teórico y analítico, se analiza el caso de la democratización de la política hídrica de Cataluña en el contexto de España y la normativa europea. Para ello se describe y relata brevemente la experiencia del proceso deliberativo para luego destacar los resultados alcanzados y las claves del éxito a la hora de destrabar las desconfianzas y formular una política pública. Resultados: La hipótesis y principal hallazgo de la investigación es que, las condiciones que permiten generar confianza en los procesos deliberativos, son: diversidad de actores (interacción con el otro); reglas y procesos claramente definidos y vinculados a decisiones finales que se tomarán con ejercicio de autoridad; y actitudes de respeto. Discusión: Lo significante del trabajo es ofrecer claves derivadas de un análisis empírico de un caso para pensar en cómo construir la doble confianza y alentar los procesos deliberativos que nuestras democracias necesitan. En dicha línea, el trabajo avanza en la construcción de una alternativa que, apelando a la participación ciudadana y deliberación entre ciudadanos y administradores públicos, genere una democratización de las decisiones públicas sin renunciar al imprescindible ejercicio de autoridad que implica aprobar cualquier política pública.

PALABRAS CLAVE: políticas públicas; confianza; deliberación; política hídrica; Cataluña.

Recibido en 14 de Junio de 2017. Recibido en 17 de Febrero de 2018.

\section{Introducción ${ }^{1}$}

${ }^{1}$ Agradecemos las sugerencias y comentarios de los dictaminadores anónimos de la Revista de Sociologia e Política.

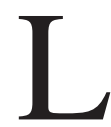

os griegos de la antigüedad asumieron que eran ellos mismos, sin esperar intermediaciones divinas, los responsables de resolver sus propios problemas y de construir sus propios proyectos de futuro. Y a través de esta humanización de los problemas y de las soluciones inventaron la política. Ya no se limitaban a esperar los designios de los oráculos, sino que decidían y actuaban. Los seres humanos tomaron las riendas de su destino y se convirtieron en los protagonistas de la historia. Sustituyeron, audazmente, a los Dioses.

Los seres humanos ocupamos, así, el centro del escenario y asumimos el reto de gobernarnos; es decir, de resolver nuestros conflictos a través de nuestras propias fuerzas y nuestros propios proyectos colectivos. Asumimos la responsabilidad, lo cual supuso un doble ejercicio de confianza y de desconfianza: confianza en nuestras capacidades y desconfianza frente al reconocimiento de nuestras debilidades. No es de extrañar, por lo tanto, que para entender la política debamos remitirnos, en primer lugar, a este singular binomio confianza - desconfianza y, en segundo lugar, a cómo éste impregna y articula nuestras instituciones político-administrativas. J. Dunn se refería a esta centralidad cuando afirmaba que "la confianza mutua se encuentra en el núcleo de todos los procesos políticos" (Dunn 1993, p.641).

Al hilo de estas primeras reflexiones, dedicaremos las siguientes páginas a desarrollar un argumento que pretende situar este binomio confianza - desconfianza en el centro del debate sobre el funcionamiento de nuestras de- 
mocracias y sobre la eficacia de sus políticas públicas. Como intentaremos mostrar, estos conceptos enraízan con el pensamiento político clásico y, simultáneamente, estarían recuperando una vigencia que, como mínimo, nos habría pasado desapercibida a los que nos dedicamos al análisis de las políticas públicas. Para desarrollar nuestro argumento, organizaremos el artículo a partir de tres grandes apartados.

En primer lugar, usaremos el binomio confianza - desconfianza para distinguir entre los dos principales modelos democráticos: la democracia de los antiguos y la democracia de los modernos. Una distinción que ha de permitirnos observar la relevancia de este binomio para entender las peculiaridades y las características de cada modelo. Esbozaremos, de este modo, unos tipos ideales que usaremos para comparar el papel que se les asigna tanto a los gobernantes como a los gobernados en cada uno de ellos.

En segundo lugar, a partir de la relación que se estable entre política y administración, atenderemos a cómo cada modelo democrático ha impactado sobre el funcionamiento de la administración y, más concretamente, de las políticas públicas. En realidad, para ser más precisos, no nos adentraremos en el poco conocido mundo de la administración de la Grecia clásica, sino que nos concentraremos en el funcionamiento de la administración pública weberiana asociada a la democracia de los modernos y, sobretodo, en la crisis que está sufriendo en la actualidad. Una crisis que transcurre en paralelo a la propia crisis de la democracia liberal y que introduce no sólo el debate sobre la democratización de la democracia sino sobre el fracaso y el colapso de las políticas públicas. Un debate complejo en el que, a nuestro entender, el binomio confianza-desconfianza puede arrojar alguna luz.

Finalmente, tras unos apartados de carácter eminentemente reflexivo, dedicaremos la tercera parte del artículo a ilustrarlos con un ejemplo concreto: la democratización de la política hídrica en Catalunya y su lectura a partir de una renovada articulación de la confianza y la desconfianza tanto en los gobernantes como en los gobernados.

No pretendemos, al menos en este momento, alcanzar ninguna conclusión definitiva sino, de forma más modesta, ofrecer algunos argumentos para justificar la utilidad del binomio confianza - desconfianza a la hora tanto de entender los límites de nuestras políticas públicas como de proponer vías para mejorar su eficacia en un contexto sumamente complejo.

\section{Modelos democráticos y articulaciones del binomio confianza-desconfianza}

El término confianza dispone de una larga tradición en el pensamiento político y, tal como nos recuerda Montero, Zmerli \& Newton (2008), lo encontramos en los textos de autores clásicos como Hobbes, Locke, Tocqueville, Weber o Parsons.

La confianza es un concepto difícil de capturar. A veces refiere a actitudes individuales socialmente orientadas, otras a percepciones racionales, otras a creencias pre-racionales desarrolladas en la socialización primaria. Una definición de mínimos de confianza la resumiría como las expectativas positivas que tienen los sujetos sobre las intenciones y los comportamientos de otros sujetos u organizaciones, que se resuelve en un estado intermedio entre el saber y el no saber y, por cierto, puede ser decepcionada (Landau 2009; Güemes 2016).

En el marco de esta idea, se destacan tres dimensiones de la confianza: una cognitiva que supone un razonamiento basado en información que se interpreta, otra afectiva sustentada en emociones y que implica la decisión de suspender la 
duda respecto al otro y actuar "como sí" fuera digno de confianza; y una sociológica-rutinaria que conduce a sostener la ficción y la expectativa de que todos los otros se comportarán de modos adecuados (Lewis \& Weigert 1985; Möllering 2006).

Este concepto - confianza social - ha jugado un papel relevante en una parte sustantiva de la literatura reciente y se ha utilizado principalmente para argumentar como "la predisposición a confiar en los demás ayuda a reducir la complejidad social y ofrece una solución al problema de los extraños" (Güemes 2016, p.17). Ello explicaría su importancia en tanto que generadora, a partir de determinadas expectativas sobre el comportamiento de los otros y de las instituciones, de dinámicas de colaboración (Pollit, Bouckaert \& Löffler 2006) fundamentales para la democracia, el desarrollo económico, la eficacia y capacidad de gobernar, el bienestar social e, incluso, la felicidad (Gambetta 1988; Putnam 1993; Luhmann 1996; Levi \& Stoker 2000; Rothstein 2000; Sztompka 2000; Hardin 2002; Uslaner 2002; Tilly 2005; Innerarity 2015).

En el estudio de caso observaremos cómo la confianza puede emerger de espacios de diálogo y colaboración entre ciudadanos y representantes de gobierno. Esta idea se asienta en una literatura novedosa que sostiene que alentar esfuerzos de construcción comunitaria y promover una cultura organizacional que favorezca la participación ciudadana potencia la creación de confianza (Yang 2005). El proceso de restauración y mantenimiento de confianza mutua debe iniciarse o potenciarse desde la propia administración, estimulando estrategias que involucren al ciudadano en la gestión de lo público (Van de Walle \& Lahat 2012; Yang 2005).

El binomio confianza - desconfianza no se utilizará aquí para definir una relación entre individuos sino para identificar una institución crucial para entender el funcionamiento de la democracia. Una "institución invisible" - usando la expresión de Arrow (1974) - que complementa las dinámicas procedimentales con una dimensión moral que influiría decisivamente en el rendimiento de nuestras instituciones político-administrativas. La confianza, de este modo, "se constituye como un problema central en la historia de las democracias" (Rosanvallon 2007, p.24). No se trata únicamente de observar como la confianza entre personas mejora las capacidades de los gobernantes sino, también, de analizar como los sistemas político-administrativos democráticos funcionan a través de determinadas asignaciones y distribuciones de confianzas y desconfianzas.

Esta es la preocupación central de nuestro trabajo y el ámbito en que pretendemos realizar una contribución al debate sobre la relación entre la confianza y el funcionamiento de nuestro sistema político democrático. Nos centraremos, pues, en primer lugar, en observar cómo los conceptos confianza y desconfianza tienen ya sus antecedentes en la antigua Grecia (la llamada democracia de los antiguos) y en cómo éste binomio se transforman con la llegada del modelo liberal - la democracia de los modernos.

II.1. Democracia de los antiguos: confianza en los ciudadanos y desconfianza en los gobernantes

Frente a la areté aristocrática que ensalzaba el valor y la valentía en la batalla, ya en el siglo VI a. de C. empezó a valorarse la areté cívica, que subrayaba virtudes vinculadas a la moderación, el equilibrio y el compromiso colectivo. De manera muy ilustrativa, los famosos guerreros griegos - los hoplitas - ya no eran superhombres solitarios sino soldados que dependían los unos de los otros. Sus escudos cubrían parcialmente a su compañero de batalla, de manera que la cooperación era indispensable tanto para dotarlos de fuerza como para protegerlos de las agresiones exteriores. El poder guerrero de los 
griegos - que se impuso durante prácticamente dos siglos en la cuenca del Mediterráneo - dependía así de la confianza entre unos soldados que, literalmente, dependían unos de otros (Finley 1992).

También en la vida civil, la confianza en las capacidades humanas estaba imponiéndose y dando lugar a la aparición de las primeras instituciones democráticas. Se empezó a concebir a los ciudadanos como seres dotados de logos (razón) y de hybris (moderación) y, consecuentemente, se debía permitir su participación activa en las tareas de gobierno. Las nuevas constituciones políticas que aparecieron entre el siglo VI y el siglo V a. de C. en las polis griegas representan la institucionalización de esta razón humana o, si se prefiere, la articulación de la confianza, entendiéndola como la capacidad de los ciudadanos para tomar decisiones. Unos ciudadanos que no sólo estaban capacitados para tomar decisiones de gobierno (democracia directa) sino también para resolver disputas judiciales. Así, la confianza en la capacidad de juicio de los ciudadanos se tradujo en la existencia de unos jurados populares muy alejados del énfasis que actualmente ponemos en la división de poderes y en la imparcialidad técnica de la justicia. En otros términos, hoy ya no confiamos la justicia a los ciudadanos sino a un colectivo especializado en su aplicación (Sartori 1987; Requejo 1990).

Por otro lado, simultáneamente, en esta democracia de la antigüedad se impuso también la desconfianza hacia los gobernantes, articulada, sobre todo, a través del rechazo a la representación. En el ágora se discutía y se tomaban las decisiones por unanimidad, evitando el uso del voto como forma de representar la voluntad general. Usando nuestros términos, se confiaba más en la capacidad de hablar y alcanzar acuerdos que en el uso de mecanismos agregativos destinados a condensar las voces ciudadanas. En la misma dirección, la elección de un cargo tampoco se sometía a votaciones, sino que se usaba el método del sorteo. Este es un dato muy significativo, pues suponía que se podía confiar en cualquier ciudadano a la hora de asumir una responsabilidad. Por el contrario, someter esta selección a procedimientos electorales era considerado una debilidad democrática, pues implicaba que los más audaces, los más ricos o los mejores oradores siempre serían elegidos. Finalmente, la desconfianza hacia los gobernantes se manifestaba también en la posibilidad de ser sometidos al juicio de los ciudadanos a través de unos jurados populares que podían sancionarles no sólo por incumplimientos penales sino también por el fracaso de sus políticas. El ostracismo era la peor sanción que podía imponerse a esos gobernantes fracasados a los que se les obligaba a abandonar la comunidad. En realidad, se les había retirado la confianza (García Gual 1995).

En resumen, tal como vemos en la Cuadro 1, la democracia de los antiguos se caracteriza por confiar en los ciudadanos y desconfiar de los gobernantes. No profundizaremos en este tema, pero es evidente que este peculiar binomio confianza-desconfianza se reflejaba en las formas de tomar decisiones y en la estructura institucional de estas democracias clásicas y que no entenderíamos sus rasgos más distintivos sin referirnos a él (Cuadro 1).

\section{II.2. Democracia de los modernos: desconfianza en los ciudadanos y confianza en los gobernantes}

La democracia de los antiguos sufrió una intensa crisis y el término democracia fue apartado de la centralidad del debate político durante más de 20 siglos. Podríamos intentar explicar esta situación como una crisis de confianza en unos ciudadanos que se mostraron manipulables y mediocres, pero no tenemos tiempo para ello. Tan sólo recordar -como ejemplo de desconfianza democrática- una de las citas más conocidas de Platón: 
Cuadro 1 - Modelos de democracia y binomio confianza - desconfianza

\begin{tabular}{lcc}
\hline & $\begin{array}{c}\text { Gobernantes } \\
\text { que sí confían }\end{array}$ & $\begin{array}{c}\text { Gobernantes } \\
\text { que no confían }\end{array}$ \\
\hline Ciudadanos que sí confían & Situación deseable & $\begin{array}{c}\text { Democracia } \\
\text { de los Modernos }\end{array}$ \\
Ciudadanos que no confían & $\begin{array}{c}\text { Democracia } \\
\text { de los Antiguos }\end{array}$ & Situación actual \\
\hline
\end{tabular}

Fuente: Elaboración propia.

"Los ciudadanos se hacen susceptibles hasta el extremo de revelarse ante la menor apariencia de coacción. Y llegan, finalmente, a no obedecer las leyes escritas, pues no aceptan tener señor alguno [...] A la insolencia le llaman cultura; a la anarquía, libertad; al libertinaje, magnificencia; a la desvergüenza, valor" (Jaeger 1962, p.178)

Necesitamos, en cambio, dar un enorme salto en el tiempo y situarnos en 1787, año en que se aprueba la Constitución de Filadelfia y que adoptamos como hito fundacional de la democracia de los modernos. Como sabemos, la Constitución de Filadelfia puede considerarse como el punto de partida de la llamada democracia de los modernos. Un modelo que se ha impuesto durante más de dos siglos y que se basaba en un equilibrio entre la voluntad (más o menos aparente) de otorgar el poder al pueblo y la voluntad (más o menos explícita) de desautorizar a este mismo pueblo para su ejercicio efectivo. Un ejercicio que, alternativamente, se reservaba a una elite de profesionales y de políticos electos. Se trataba, en otros términos, de construir un sistema de intermediación que sitúa el poder formal en el pueblo pero que reserva su ejercicio efectivo a un grupo de representantes de este poder popular (Madison, Hamilton \& Hay 2009).

Este original diseño institucional parte de la desconfianza hacia las tendencias explosivamente revolucionarias del pueblo, que deben ser vehiculadas y controladas a través de una Constitución escrita, la división del poder, los sistemas de elecciones de representantes, la distribución territorial de los gobiernos, etc. La democracia liberal se preguntó cómo estabilizar el conflicto entre los derechos de una minoría de propietarios y los de una mayoría que no lo eran, y la respuesta fue una densa red de intermediación de proponía una nueva articulación del binomio confianza- desconfianza: confianza en los gobernantes (intermediarios electos) y desconfianza en los ciudadanos (que pueden amenazar los derechos de propiedad). Tal como lo expresaba magistralmente Crossman (1977, p.37), se trataba de "crear un sistema tan complejo que no dejara pasar ni una gota de sentimiento popular".

\section{II.3. La actual perversión de la doble desconfianza y la necesidad de articular la doble confianza}

Los dos cuadrantes que en la Cuadro 1 ocupan la democracia de los antiguos y la democracia de los modernos se encuentran hoy con enormes dificultades. Por un lado, la alternativa de la Grecia clásica no sólo colapsó, sino que su aplicabilidad a las sociedades actuales es como mínimo problemática. Por otro lado, el modelo liberal dominante e incuestionable hasta hace pocos años, se ha visto desafiado por una idea que torpedea su línea de flotación: no nos representan. Una sentencia que impugna la esencia de la democracia de los modernos y que se ha convertido en el punto de partida de una crisis que no para de agrandarse.

Así pues, parece que no podemos confiar ni en los ciudadanos (que se muestran mediocres y con dificultades a la hora de traducir sus pulsiones en 
decisiones colectivas) ni en los gobernantes (que ya no nos representan y que ejercen una intermediación que no aporta valor añadido). Frente a esta situación, nos encontramos con diversas alternativas en disputa:

- En primer lugar, nos encontramos con aquellos que pretenden recuperar la confianza de los representantes y que, en consecuencia, nos proponen diferentes estrategias para potenciar su confiabilidad: el acceso abierto a la información pública, la transparencia y la rendición de cuentas son sus mantras (Behn 2001; Lathrop \& Ruma 2010).

- En segundo lugar, algunos consideran la posibilidad de construir ágoras virtuales y, de este modo, recrear una versión actualizada de la democracia de los antiguos. En el eje de esta propuesta se encuentra una renovada confianza en la capacidad de los ciudadanos para tomar decisiones y abordar sus propios problemas (Ibarra, Martí \& Gomà 2002).

- En tercer lugar, moviéndonos hacia un cuadrante que no aparece en la Cuadro 1, podríamos imaginar una situación que combine la confianza en los ciudadanos con la confianza en los gobernantes. Una situación de doble confianza que, a nuestro entender, sería crucial para ofrecer una adecuada respuesta a los retos colectivos de este nuevo milenio. Una situación donde el ciudadano recuperaría el papel que le había otorgado la democracia de los antiguos sin renunciar al rol de los gobernantes en contextos de mayor dimensión demográfica y complejidad social (Fiskin 2011).

En este artículo pretendemos avanzar en la construcción de esta tercera alternativa que, en realidad, se basa en la articulación de un nuevo binomio confianza-confianza. Posiblemente, como sugiere el trabajo de Wences y Güemes (2016), bajo un modelo de democracia republicana pluralista e inclusiva que, además de articular representación, participación y deliberación y garantizar derechos sociales, culturales y políticos, dirija su atención a incentivar la reciprocidad y el mutuo respeto la confianza tiene más sentido y encuentra mayor asidero, mejorando la eficacia de los gobiernos. Para ello necesitamos dar un paso más y trasladarnos de la teoría democrática al análisis de las políticas públicas. En este terreno, como veremos en el siguiente apartado, necesitamos superar una situación donde las decisiones de política pública se adoptan por expertos profesionales (evitando así la doble desconfianza hacia ciudadanos y políticos) y movernos hacia un nuevo escenario donde la ciudanía participa y se genera una democratización de las decisiones públicas, aunque sin renunciar al imprescindible ejercicio de autoridad que implica aprobar cualquier política pública (construyendo una doble confianza hacia ciudadanos y políticos).

Tal como se muestra en la estructura de los procesos participativos, se trata de combinar el reconocimiento de la autoridad (expresada en la persistencia de la democracia representativa) con el reconocimiento de la participación ciudadana (expresada en la elaboración deliberativa de las políticas públicas). La autoridad se refiere al quién de las decisiones públicas, mientras la deliberación se refiere al cómo éstas se adoptan (Brugué 2012). Usando nuestros conceptos, estamos proponiendo construir un escenario donde confiar tanto en la capacidad de los ciudadanos para participar en la toma de decisiones como en la capacidad de los gobernantes para, dotados de autoridad, tomar las decisiones que les corresponden. Lo desarrollamos a continuación y los ilustramos en el tercer apartado con el ejemplo de la política hídrica. 


\section{De la administración de la desconfianza a las políticas de la confianza}

En el apartado anterior hemos explicado como los dos tipos ideales de democracia - la de los antiguos y la de los modernos - responden a una determinada combinación de confianza/desconfianza en los ciudadanos y en los gobernantes. Ahora, ya situados en el contexto de la democracia representativa moderna nos interesa destacar algunos rasgos distintivos de sus políticas públicas. En concreto, pretendemos mostrar cómo sus políticas públicas podrían y/o debería trasladarse del cuadrante que combina democracia representativa con un proceso de toma de decisiones sin participación ciudadana (administración moderna construida sobre la desconfianza) al cuadrante donde, sin renunciar al rol representativo de los gobernantes, se incorpora la participación de la ciudadanía en los procesos decisionales (administración deliberativa basada en la doble confianza).

Una versión de esta hipótesis la encontramos en el trabajo de Warren (1999). Para este autor, la política consiste en tomar decisiones de obligado cumplimiento en situaciones de conflicto sobre bienes escasos, de manera que se trata de un contexto que amenaza permanentemente los intereses de unos y otros. Un contexto que sólo puede operar bajo condiciones de confianza, aunque, al mismo tiempo, esta misma confianza se encuentra permanentemente bajo amenaza. Warren define esta situación como el "dilema democrático de la confianza" e identifica tres soluciones teóricas: la neoconservadora, la que se propone desde la óptica de la elección racional y la deliberativa.

La opción neoconservadora considera que la única forma de mitigar el dilema pasa por minimizar el número de decisiones colectivas tomadas por las instituciones públicas y por maximizar aquellas que se toman en entornos de confianza natural: las comunidades y el mercado (Fukuyama 1996).

La teoría de la elección racional, por su parte, identifica la confianza con la creencia en que otra persona o institución tiene un interés en nuestro bienestar. El dilema se resuelve, pues, cuando se diseñan instituciones que funcionan bajo estos incentivos positivos (Hardin 2002).

Finalmente, la solución deliberativa considera que el dilema se supera a través de la complementariedad entre la deliberación democrática y la confianza mutua; es decir, cuando el propio proceso deliberativo es generador de confianza y, al mismo tiempo, la confianza facilita el proceso deliberativo (Gutmann \& Thompson 2004).

Al igual que el propio Warren, adoptamos la posición deliberativa y lanzamos la hipótesis de que para hacer frente al actual colapso gubernamental deberíamos superar las dinámicas administrativas basadas en la desconfianza y desplazarnos hacia una construcción deliberativa - y, por lo tanto, basada en la confianza - de las políticas públicas. A continuación, desarrollamos esta hipótesis que, en el tercer apartado, contrastamos con un caso específico.

\section{III.1. Administración moderna: la articulación de la desconfianza}

La democracia de los modernos llegó acompañada de un modelo de administración que confiaba en el conocimiento experto y desconfiaba de las capacidades tanto de los gobernantes como de los ciudadanos a la hora de involucrarse en el diseño de las políticas públicas. Wildavsky (1979) ilustra esta posición en el propio título de su afamado libro, Speaking Truth to Power. Siguiendo la estela de la racionalidad tecnocrática weberiana, se considera que los profesionales expertos tienen acceso a la verdad y que, en consecuencia, el proceso decisional tiene que confiarse plenamente a sus criterios. Incorporar las opiniones de gobernantes y ciudadanos es absurdo, pues se trata de opiniones 
sin fundamento en las que, usando otra vez nuestro término de referencia, no podemos confiar.

El resultado ha sido una administración encerrada en sus propias certidumbres y ajena a cualquier aportación externa. Una administración que únicamente confía en las indicaciones del abstracto conocimiento experto y en los mandamientos de sus procedimientos, y que se muestra hostil a cualquier perspectiva alternativa. Podríamos definir esta administración como una forma organizada de la triple desconfianza: hacia los gobernantes, hacia los ciudadanos y hacia sus propios recursos humanos.

- La desconfianza hacia los gobernantes se ejemplariza en la conocida dicotomía wilsoniana, según la cual el mundo de la política debe estar radicalmente separado del mundo de la administración. El primero funciona a través de discusiones y opiniones, mientras que el segundo se rige por conocimientos y certidumbres. Los políticos, por lo tanto, una vez han trasladado a la administración las órdenes de ponerse a trabajar, deben mantenerse ajenos del diseño experto de las políticas públicas.

- La desconfianza hacia los ciudadanos se basa en el hecho de ser considerados como no competentes y se manifiesta en formas endogámicas de actuación. La administración monopoliza el conocimiento, mientras que los ciudadanos - usuarios no tienen más que esperar los efectos de sus actuaciones. La administración moderna ha sido, consecuentemente, muy reticente a cualquier forma de participación ciudadana; pues desconfía de su utilidad y sospecha que únicamente sirve para perder tiempo y dinero.

- La desconfianza hacia los empleados públicos también implica que sólo se espere de ellos que cumplan las normas, sin explicarles las razones de su trabajo ni preguntarles nada sobre cómo mejorarlo. En realidad, la densidad de los procedimientos administrativos, de los organigramas y de los controles ex ante son una manifestación de la desconfianza; de la necesidad de vigilarnos mutuamente, de asegurar que nadie se salga del guion y de garantizar que nadie decida nada por su cuenta.

La base de nuestra administración tradicional es, pues, una peculiar combinación del binomio confianza-desconfianza: confiamos en los procesos y desconfiamos de las personas, confiamos en los técnicos y desconfiamos de los ciudadanos, confiamos en los directivos públicos y desconfiamos de los gobernantes electos. La administración es una máquina; y son los mecánicos los que deben hacerse cargo de su buen funcionamiento y no unos conductores que, demasiado a menudo, se caracterizan por sus comportamientos temerarios.

El problema es cuando los mecánicos tienen el coche en perfecto estado, pero nadie sabe muy bien hacia donde conducir el vehículo. Esto es lo que puede haber pasado durante las últimas décadas con algunas administraciones públicas. Los gobiernos han sido capaces de mejorar el funcionamiento de la máquina administrativa, aunque las políticas han perdido el rumbo y se muestran incapaces de resolver los problemas. Es decir, hemos mejorado en la prestación de servicios públicos y, al mismo tiempo, paradójicamente, las políticas públicas son cada vez más incapaces de transformar la realidad sobre la cual pretenden incidir (Stone 2002).

Detectamos, pues, una creciente incapacidad de gobernar nuestras sociedades, entendiendo por "gobernar" - usando su sentido etimológico - la capacidad de llevar el timón, de dirigir la comunidad hacia un determinado destino. Una incapacidad que, como ya hemos anticipado, encontraría su 
explicación en la doble desconfianza en los gobernantes y en los gobernados. Una desconfianza que se traduce en una parálisis de las políticas públicas: los gobernantes no confían en la capacidad de los gobernantes para tomar decisiones (y son capaces de paralizarlas), mientras que los gobernantes no confían en la capacidad de los ciudadanos y no los incorporan en los procesos decisionales (volviendo, así, a paralizar sus iniciativas).

\section{III.2. Del fallo al colapso de las políticas públicas}

La literatura académica ha analizado la dificultad de desplegar políticas públicas en un contexto como el que hemos presentado (Geyer \& Rihani 2010). Incluso ha acuñado el término policy failure para referirse a lo que Bovens y Hart (1998) llaman el "fiasco de las políticas públicas". Desde esta perspectiva, la lógica tecnocrática y simplificadora con la que operan las instituciones públicas entraría en colisión con la complejidad de la realidad sobre la cual pretende intervenir. Una asimetría letal para las políticas públicas, que fracasarían en su intento de abordar desde perspectivas simplificadoras (segmentación y especialización) realidades complejas (poliédricas y multidimensionales).

La Ilustración nos situó en un escenario marcado por la confianza y el control. Un contexto en el que nos aproximábamos al mundo desde la seguridad de poder conducirlo hacia un futuro que, además, siempre mejoraría tanto el pasado como el presente. Algunos autores han definido este escenario como el paradigma del orden. Es el paradigma de la revolución industrial y de la racionalidad tecnocrática; un modelo donde el conocimiento nos permite acceder a las leyes que rigen la realidad $\mathrm{y}$, consecuentemente, también a las herramientas (políticas públicas) para intervenir sobre ella (Horgan 1996; Wilson 1998).

Hoy, en cambio, parece que las dudas han sustituido a las seguridades, descubriendo los límites de un conocimiento que ya no explica una realidad desbordantemente compleja ni permite intervenciones controladas sobre la misma (Scott 1988). Una complejidad que no es tan solo un atributo de la realidad sino algo que debemos integrar en nuestra forma de entenderla y de intervenir sobre ella. El fallo de las políticas se vincula, por un lado, a la complejidad irreductible de los problemas sobre los cuales pretende incidir y, por otro lado, a la simplicidad de los planteamientos y de los instrumentos de intervención. Esta nueva complejidad - a la que nos hemos referido como wicked problems - reclama ser asumida en las propias políticas públicas a través de la racionalidad deliberativa (Ritter \& Webber 1973).

En este trabajo proponemos trasladarnos del "fallo de las políticas" al "colapso de las políticas". No se trata de un simple cambio terminológico. Pretendemos, más bien, mover el foco desde las dificultades de implementar políticas públicas hacia algo más básico: la incapacidad de diseñarlas y ponerlas en funcionamiento. Mientras que el fallo de las políticas nos remite a un estudio de las condiciones en las que se produce el ciclo de las políticas públicas, su actual colapso ni siquiera alcanza este ciclo y, siguiendo con nuestra hipótesis de trabajo, se explicaría por lo que antes hemos denominado el doble déficit de confianza.

Desde este punto de vista, el binomio desconfianza - desconfianza no se limita a dificultar la implementación de las políticas, sino que nos incapacita para diseñarlas. Se trata de un bloqueo que tiene que ver con la incapacidad de ejercer las actuaciones político-democráticas más básicas cuando no disponemos ni de unos pocos gramos de su ingrediente esencial: la confianza. Sin un mínimo de confianza en los ciudadanos la democracia no es únicamente que no 
funcione adecuadamente, sino que ni siquiera consigue ponerse en funcionamiento. Y, del mismo modo, sin cierta confianza en nuestros gobernantes, los incapacitamos no sólo para tomar decisiones adecuadas, sino que impedimos que las tomen.

III.3. Administración deliberativa: construyendo la doble confianza

Frente esta situación, que la literatura especializada ha bautizado como policy failure y que nosotros hemos preferido calificar como de colapso de las políticas públicas, han aparecido propuestas en dos direcciones. En primer lugar, desde el enfoque de la excelencia empresarial se sugiere que la gestión de los servicios públicos debería contar con las ideas y las voces de los empleados y de los clientes. Estos no sólo son dignos de confianza sino que se convierten en los factores claves para explicar el éxito de las organizaciones. Estas propuestas, que encontramos en los trabajos seminales de Peters y Waterman (1982) y Osborne y Gaebler (1998), se han centrado en el ámbito de la prestación de servicios y, en consecuencia, no han abordado las dificultades de las políticas públicas.

En segundo lugar, ahora ya en el ámbito de las políticas públicas, han proliferado las aportaciones que han situado el acento en la necesidad de tomar decisiones de forma deliberativa; contando con los diversos puntos de vista que se encuentran tanto en las diferentes unidades de una organización como entre los múltiples agentes externos a la misma. El argumento central radica en la superioridad de la racionalidad deliberativa a la hora de abordar los problemas complejos que hoy debemos afrontar (Gutmann \& Thompson 2004; Hajer \& Wagenaar 2003; Wagenaar 2007).

Una administración que aborda el proceso decisional desde la racionalidad deliberativa debe abrirse al exterior y establecer diálogos entre los diferentes puntos de vista. Y esto únicamente se puede realizar desde la confianza. Más allá del debate sobre los diversos métodos de participación ciudadana y de transversalidad organizativa, la clave se encuentra en revertir una administración genéticamente desconfiada. No es casualidad que en los últimos años éste sea un término que ha proliferado en la literatura (Child \& Faulkner 1998; Agranoff \& McGuire 2003), aunque su traducción en la práctica ha sido más lenta y no exenta de límites (Elster 1998).

En el próximo apartado nos acercaremos precisamente a un caso concreto en el que una política pública compleja ha sido adoptada desde el diálogo.

El estudio de caso que presentaremos tiene la virtud metodológica de combinar en forma flexible estilos interpretativos y empiristas de investigación, apelando a la construcción de un relato narrativo que conecta coherentemente los acontecimientos y recupera el contexto histórico en el que se insertan las variables. Ciertamente, los hallazgos y conclusiones de un análisis de caso único no son generalizables, pero suelen generar hipótesis más complejas (Yin 1984). A partir de este caso, veremos cómo la confianza ha sido un elemento importante, simultáneamente como instrumento para favorecer el diálogo y como resultado del propio proceso de diálogo. Una confianza que se otorga a los diversos actores involucrados en la política pública y que, también, se traslada a aquellos que finalmente deberán tomar la decisión. Una doble confianza que expresa la articulación autoridad pública / participación ciudadana; una articulación difícil de alcanzar, pero sin la cual difícilmente podremos desplegar políticas públicas en los contexto de alta complejidad con los que hoy nos enfrentamos (Brugué 2014). 


\section{El ejemplo de la política hídrica: la articulación de la doble confianza}

\footnotetext{
${ }^{2}$ En este artículo usamos el caso de la política hídrica propiciada por la DMA sólo como un ejemplo y, por lo tanto, no entraremos en sus múltiples detalles. Todos los datos e informaciones utilizadas se derivan de una investigación ya concluida y financiada por el Ministerio de Ciencia e Innovación que llevaba por título "Democracia Deliberativa y Política de Agua: Experiencias de Participación en el Contexto de la Directiva Marco del Agua (DMA-PART)" (CSO2009-09880), 2009-2012.

${ }^{3}$ Del proyecto de investigación en el que nos basamos, disponemos de algunas publicaciones donde se detallan los contenidos del trabajo realizado (Espluga $e t$ al., 2011; Parès et al., 2014; 2015; Rabelo et al., 2014)
}

El caso que vamos a analizar se refiere a la elaboración y posterior aprobación, tras un proceso participativo, de los Planes de Gestión de las Cuencas Internas de Cataluña.

También es necesario subrayar que la política de agua es una política de alta complejidad técnica y de un intenso contraste de intereses. Una complejidad que estimula la doble desconfianza y que, siguiendo los argumentos esgrimidos en el apartado anterior, tiende a bloquear la política pública (Ostrom 1990)².

La Directiva Marco del Agua europea (DMA) establecía la obligación de que los responsables de todas las cuencas hídricas europeas aprobaran (confianza en los gobernantes), tras procesos de consulta pública (confianza en los ciudadanos), sus planes de gestión antes de 2009. De las 18 cuencas hídricas españolas, sólo las cuencas internas de Cataluña pudieron aprobar prácticamente en plazo su plan de gestión, mientras que el resto, debido a las dificultades técnicas y, sobre todo, políticas ya reseñadas, vieron como su aprobación se retrasaba entre 3 y 5 años. Es decir, exceptuando el caso que nos proponemos analizar, se produjo el colapso de la política pública ${ }^{3}$.

Nuestra hipótesis es que el proceso de participación ciudadana sólo se realizó con intensidad y convicción en el caso catalán (confiando en la capacidad de los múltiples actores sociales, económicos o ambientales), de manera que sólo la autoridad hídrica catalana (ACA) se ganó la suficiente autoridad (y confianza) para desbloquear la política pública y permitirle adoptar una decisión ciertamente compleja. El proceso de deliberativo que acompañó la aprobación del Plan de Gestión de las cuencas internas catalanes puede, pues, ser interpretado como un ejemplo de cómo la doble articulación de la confianza contribuye al desarrollo de políticas públicas.

Para desarrollar esta hipótesis a continuación, en primer lugar, introducimos la experiencia deliberativa derivada de la aplicación de la DMA en Cataluña; en segundo lugar, ofrecemos una descripción somera del proceso deliberativo; y, en tercer lugar, destacamos los resultados alcanzados en términos de confianza y desbloqueo de la política pública.

\section{IV.1. La DMA como punto de partida}

La DMA actuó como la palanca para impulsar, en Europa, el desarrollo de una nueva política que pretendía asumir la complejidad y la diversidad de lógicas y factores que intervienen en la gestión del agua. La nueva política debía concretarse en el llamado Plan de Gestión del Distrito de la Cuenca Fluvial de Cataluña (Videira et al., 2003; Boyden 2008).

La Agencia Catalana del Agua (ACA), dependiente del departamento de Medio Ambiente del gobierno autónomo, fue el órgano responsable de implementar la DMA en Cataluña. Respecto al proceso participativo, la Agencia constituyó una unidad específica para el fomento de la participación ciudadana y, a la vez, contó con la colaboración de la Dirección General de Participación Ciudadana (DGPC) del Departamento de Relaciones Institucionales y Participación. Esta colaboración supuso una importante inversión, tanto económica como humana, por parte de la administración de la Generalidad de Cataluña en el despliegue de la DMA (ACA 2006; 2010).

Por otra parte, el calendario del proceso fue muy dilatado en el tiempo. No es frecuente encontrarse con una política que permita dedicar 5 años sólo a la preparación y la discusión de sus contenidos. Esta situación fue propiciada por la propia DMA, la cual imponía un calendario que se iniciaba en 2003 y que 
${ }^{4}$ Utilizamos el concepto "deliberativo" ya que, a pesar de que la DMA usaba los términos "consulta" o "participación", los responsables de su adaptación al caso catalán utilizaron explícitamente tanto el término como la teoría deliberativa a la hora de diseñar el proceso que estamos resumiendo. permitía desplegar una fase de preparación y debate que abarcaba el período 2004-2009.

Finalmente, según los documentos de la ACA, los objetivos del proceso llamado "consultivo" eran "informar y escuchar la opinión de los ciudadanos y ciudadanas, así como de los representantes de entidades, administraciones y empresas, para debatir las propuestas sobre la gestión del agua a las diferentes cuencas catalanas" (ACA 2006, p.12). Tomando como punto de partida la valoración sobre el estado de las masas de agua y siguiendo las indicaciones de la DMA, la ACA y la DGPC diseñaron un proceso deliberativo estructurado en 5 fases $^{4}$ :

i. Fase preparatoria de los materiales divulgativos y de las bases de datos para identificar a los actores más significativos de cada cuenca.

ii. Fase informativa donde establecer el primer contacto con los actores, conocer sus impresiones, resolver sus dudas e invitarlos al proceso.

iii. Fase deliberativa para escuchar a los actores con el doble objetivo de validar el diagnóstico de partida sobre el estado de las masas de agua y recoger propuestas para, eventualmente, incorporarlas a los planes de medidas.

iv. Fase de conclusión donde se documentaban y recogían las aportaciones y las opiniones que los diversos actores vertieron durante el proceso.

v. Fase de retorno para hacer efectivo el compromiso gubernamental de evaluar las diferentes propuestas y rendir cuentas, con argumentos, sobre su inclusión o no en los planes de gestión.

\section{IV.2. Tres elementos distintivos del proceso: participantes, reglas y actitudes}

El proceso deliberativo se desarrolló durante un período relativamente largo de tiempo e incorporó un amplio abanico de actividades, de manera que su análisis no resulta una tarea sencilla de abordar (para un análisis más detallado ver Brugué et al., 2012) Lo intentaremos simplificar a partir de fijarnos únicamente tres aspectos: la diversidad de participantes a los que se dirigió, las reglas y los protocolos de funcionamiento y, de manera algo más detallada, los valores y las actitudes que permitieron construir la confianza sobre la que debe asentarse -según nuestra hipótesis- la construcción de una política pública.

\section{IV.2.1. Los participantes: presencias y ausencias}

En el conjunto del proceso participaron 2.382 personas, las cuales se identificaron como miembros de 1.812 entidades. Estos datos son bastante impresionantes en términos absolutos, aunque, más allá del dato frío, nos interesaría destacar tres aspectos del caso que estamos analizando: el primero hace referencia al esfuerzo por identificar y llegar hasta los diversos actores, el segundo nos remite al debate entre participación individual y participación asociativa, y el tercero nos sitúa en el debate entre los criterios de representatividad y diversidad a la hora de valorar un proceso deliberativo.

i. En primer lugar, un proceso de participación debe ser proactivo y no esperar a que, una vez hecha la publicidad, los participantes vayan llegando. Hay que identificarlos y dedicar esfuerzos a una invitación activa, ya que de otro modo se producirán limitaciones y sesgos en la composición de los participantes. La confianza en las capacidades de 
${ }^{5}$ Concretamente, los 2.382 participantes se distribuyeron entre los siguientes grupos: 229 agricultores o ganaderos, 290 industriales o actores económicos, 476 de entidades sociales o académicas, 517 de la administración y 122 personas a título particular. participación no puede limitarse a unos actores determinados, sino que debe ampliarse a todos los actores involucrados.

ii. En segundo lugar, en todo proceso de participación aparece la tensión entre participación individual y participación asociativa. En el caso que nos ocupa, la participación ha sido preferentemente asociativa, mientras que los individuos que se han acercado al proceso de manera individual han sido marginales. Este sesgo hacia la participación asociativa ha sido pues una evidencia, y ha supuesto efectos tanto positivos como negativos.

iii. En tercer lugar, un aspecto clave en el debate sobre los participantes es aquel que se refiere a los criterios de representatividad y/o diversidad. A menudo, especialmente cuando la participación se hace a través de entidades, se invoca a la representatividad de aquellos que toman la palabra en el proceso. Las opiniones y las posiciones que expresan no son únicamente suyas, sino que representarían a un conjunto mucho más amplio de ciudadanos. El proceso deliberativo impulsado para acompañar el desarrollo de la DMA, en cambio, no buscó la representatividad de los participantes sino la diversidad de opiniones, confiando en que la principal aportación a la política pública se encuentra precisamente en la suma de todas ellas ${ }^{5}$. Además, se evita un conflicto de representatividades que, a la postre, deriva en un debilitamiento de la confianza hacia aquellos que, dotados de autoridad, son los responsables de tomar las decisiones.

Este es uno de los debates recurrentes en el mundo de la participación, que en este caso se resolvió - aunque no de manera satisfactoria para todos - con un reconocimiento explícito de que el proceso participativo servía para escuchar y para responder a todos, mientras que la decisión final quedaba en manos de la autoridad responsable. Se trata de una forma operativa de expresar la apuesta conceptual por la doble confianza hacia los ciudadanos (a los que se escucha) y hacia los gobernantes (a quién se asigna la responsabilidad de tomar la decisión final).

\section{IV.2.2. Reglas y protocolos: tiempos y espacios para el diálogo}

El proceso deliberativo se organizó a través de 16 ámbitos territoriales, aunque con una dinámica de funcionamiento similar en todas ellas. Esta dinámica estuvo conducida por diferentes empresas profesionales, pero en todos los casos mantenía una misma secuencia. Esta secuencia, tal como se muestra en la figura 1, es la que define las reglas y los protocolos del proceso participativo.

Consideramos que este enfoque fue positivo para generar un entorno de previsibilidad y confianza. También es cierto que el modelo fue diseñado desde arriba - en concreto, desde la DG de Participación Ciudadana - y que, por tanto, podía ser percibido por algunos de los actores como un tecnocratismo impuesto. Unas buenas reglas deben ser claras y seguras, pero también compartidas por los propios participantes en el proceso. De hecho, algunos de los participantes hicieron mención a esta limitación, reclamando ser escuchados no sólo a la hora de debatir los contenidos del proceso sino también en el momento de determinar sus formas (secuencia, duración, calendario, etc.) (Figura 1).

Quisiéramos destacar también la contribución del tiempo dedicado al debate y a la construcción de relaciones y confianzas. El proceso debía conseguir que trabajaran juntos actores que tradicionalmente habían estado muy distanciados y que, además, tenían visiones e intereses muy dispares. Un calendario pausado y con oportunidades para una interacción continua contribuyó a conocer y reconocer al otro. Este proceso de conocimiento y reconocimiento puede ser 
Figura 1 - Estructura de los procesos participativos

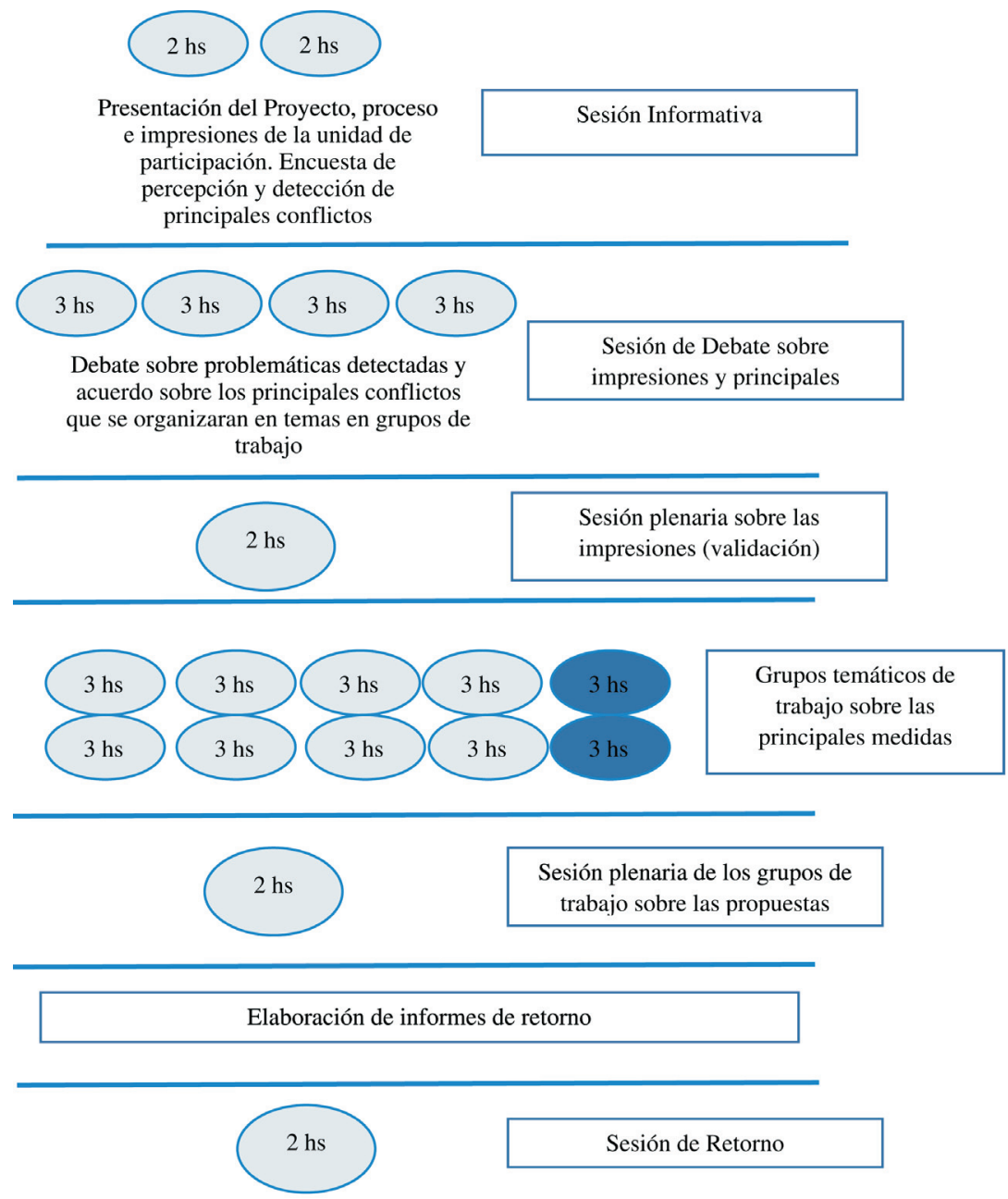

Fuente: ACA (2006).

una de las aportaciones más significativas del proceso participativo, ya que permite colocar las semillas de la confianza y estimular, así, la capacidad para desbloquear la política pública.

\section{IV.2.3. Actitudes y valores: construyendo confianzas}

Los procesos deliberativos se caracterizan tanto por unas pautas de funcionamiento como de comportamiento que se aplican - y el caso del agua es un buen ejemplo - a conflictos políticos y morales. Unos conflictos que, para ser abordados de manera constructiva, reclaman ciertos valores y actitudes por parte de los participantes. Usando un símil deportivo, la deliberación requiere que los participantes no sólo dispongan de un terreno de juego en buenas condiciones (donde intercambiar argumentos) sino que también necesitan que los propios participantes, los jugadores, se comporten siguiendo un cierto fair-play, obedeciendo ciertas reglas no escritas que regulan sus relaciones y los valores que las rigen. Nos estamos refiriendo a un conjunto de pautas de comportamiento sin las cuales difícilmente podría funcionar ni la competición deportiva ni un proceso participativo.

A partir de las afirmaciones anteriores, cabe preguntarse a través de qué actitudes y qué valores deben abordarse los legítimos conflictos en torno a una política compleja como la del agua. Descartado el modelo de una democracia 
agregativa, donde gana el que tiene más fuerza (aunque sea expresada con votos), el proceso deliberativo invoca al diálogo como instrumento para reconocer la validez de las diferentes posiciones y la necesidad de contrastarlas para generar una decisión de mayor calidad. La literatura usa el concepto "principio de acomodación" para definir la forma de conducir los desacuerdos morales que llegan a la agenda pública y que no se desactivan a través de una votación o de una posición de fuerza (Gutmann \& Thompson 2004). Se trata de ver cómo generamos acuerdos de carácter político a partir de desacuerdos morales de base.

Para avanzar en esta dirección se considera imprescindible valorar no sólo el contenido sustantivo de los desacuerdos sino también la forma en que éstos se expresan. El ya mencionado 'principio de acomodación', por tanto, pretende garantizar que las diferentes posiciones, moralmente respetables, se expresen de maneras también moralmente respetables. Se trata, con otros términos, de ponerse de acuerdo sobre la manera discrepar y sobre la forma de gestionar los desacuerdos. Es en este terreno donde el diseño y la conducción del proceso deliberativo alcanzan una importancia crucial.

¿Fue el proceso deliberativo al que nos estamos refiriendo capaz de generar unas formas respetuosas de abordar el conflicto? Este es un interrogante que hemos podido contrastar con las opiniones de los propios actores, y del que nos gustaría destacar algunos aspectos:

i. En primer lugar, el inicio del proceso deliberativo estuvo caracterizado por la desconfianza hacia la Administración y hacia otros participantes. El agua es un asunto conflictivo donde, históricamente, las oportunidades de interacción entre los diferentes actores han sido escasas, lo que contribuye a explicar estos inicios difíciles. De hecho, quizás el reto más importante del proceso era superar esta fase inicial donde los actores sólo se intercambiaban miradas desconfiadas y avanzar hacia una situación donde, desde la confianza, intercambiasen palabras constructivas.

ii. En segundo lugar, el cuidado en el diseño y la ejecución del proceso fueron clave para avanzar en la construcción de confianzas. También una gestión sincera de las expectativas de los actores, a los que se les presentó el proceso deliberativo sin despertar falsas esperanzas ni esconder sus problemas y sus limitaciones. De manera similar, se repetía que el Gobierno se tomaba en serio el proceso, pero que nadie pensara que no asumiría su responsabilidad de tomar la decisión final, incluso cuando ésta - como era evidente - no podía satisfacer el 100\% de las expectativas del $100 \%$ de los participantes.

iii. Amparados por unas reglas claras y por una adecuada gestión de las expectativas, finalmente, se propició una situación donde se estaba de acuerdo sobre cómo abordar el desacuerdo. El acuerdo sustantivo, obviamente, no se logró, pero sí se tendió a aceptar cierta manera de gestionarlo.

Para conseguir estos comportamientos es importante que el proceso esté bien diseñado, pero aún lo es más que esté bien conducido y dinamizado. $\mathrm{Si}$ traducimos este conjunto de tareas al lenguaje de la teoría deliberativa, la dinamización ha sido capaz de generar unas relaciones basadas en el respeto mиtuo. El respeto mutuo se define como un tipo de carácter democrático que va más allá de la tolerancia: no reclama sólo la aceptación pasiva del otro sino, además, una actitud favorable y una interacción constructiva con aquellos con quienes, por otra parte, se mantiene el desacuerdo. No sólo se toleran las 
${ }^{6}$ En el marco del proyecto de investigación referido en la nota número 2 se realizaron 38 entrevistas tanto a participantes de la sociedad civil como a personas de la administración pública promotora del proceso deliberativo. diferencias, sino que se admite la posibilidad de encontrar maneras de gestionarlas y de convivir con ellas.

Durante las entrevistas realizadas a los propios participantes ${ }^{6}$, se valoraron positivamente estas actitudes, que habrían contribuido al proceso a través de saber escuchar y saber intercambiar opiniones con los demás:

"No me lo esperaba [...] una enorme madurez por parte de todos, brutal [...] una normalidad democrática absoluta." [Miembro de la ACA]

"Dejando de lado dos o tres ejemplos puntuales, todo transcurrió dentro de unas formas muy civilizadas." [Industrial]

"La discusión a veces fue fuerte, pero siempre en positivo. Cada uno reclamaba lo que le aprieta en el zapato [...] pero los debates fueron constructivos." [Miembro de una organización social]

En definitiva, hay que recordar que, aparte de la influencia de los dinamizadores del proceso, conseguir el respeto mutuo depende sobre todo de la virtud cívica de los participantes, de su capacidad para defender sus intereses sin perder de vista la existencia de un interés colectivo. Sólo con ciudadanos en el sentido aristotélico, no jurídico, del término - puede desarrollarse un proceso deliberativo como el que estamos analizando y, por tanto, son los propios participantes los que explican buena parte de la bondad de sus resultados. La confianza en los ciudadanos que caracterizaba a la democracia de los antiguos reaparece, ahora, como condición para el desarrollo de determinadas políticas públicas.

Al lado del papel de los dinamizadores y de las actitudes de los participantes, hemos detectado un tercer elemento clave para el desarrollo de las sesiones de debate: la presencia y el rol que jugaron los directivos y los técnicos de la ACA. Su posición podía ser incómoda, pero en las entrevistas hemos recogido valoraciones muy positivas del trabajo que realizaron: asesorar, resolver dudas, proporcionar documentos, etc.

Sin embargo, no todos los técnicos de la ACA observaban el proceso participativo de la misma manera. Algunos compartían los objetivos, mientras que otros lo consideraban, literalmente, una pérdida de tiempo y recursos. No confiaban en poder aprender nada nuevo. Esta tensión estuvo presente durante todo el proceso, aunque la evaluación posterior detectó una progresiva aceptación por parte de aquellos más reticentes. La ACA es un organismo dominado por la racionalidad tecnocrática y, por tanto, poco habituado a las lógicas deliberativas. Aun así, el proceso parece haber generado aprendizajes también en el interior de la propia organización.

En este apartado estamos hablando de comportamientos y de actitudes, unos aspectos de carácter intangible, pero de gran importancia a la hora de evaluar los resultados de un proceso deliberativo. Barber (1984) lo expresaba con precisión cuando nos recordaba que un proceso deliberativo define un espacio donde se intercambian razones y emociones, donde ofrecemos argumentos y establecemos relaciones con los demás. En los párrafos anteriores hemos definido, en definitiva, el proceso de construcción de las confianzas mutuas.

IV.3. Los resultados del proceso: la confianza como derivada sustantiva

En este último apartado nos preguntamos sobre el tipo de relación que se estableció entre los diversos actores involucrados en el proceso deliberativo tanto sociales como institucionales. Se trata de valorar, tal como hemos establecido en nuestra hipótesis, hasta qué punto se generó el binomio confianza-confianza y cómo influyó en la aprobación final del plan de gestión de las cuencas fluviales catalanas. 
De entrada, tal como ya habíamos anticipado, resulta evidente que las relaciones comenzaron impregnadas de una fuerte desconfianza: los participantes desconfiaban de la administración y la administración desconfiaba de los participantes, mientras que los participantes representaban intereses diversos y también recelaban unos de otros. En las sesiones informativas que daban el pistoletazo de salida a los procesos deliberativos se abría un turno de intervenciones entre los asistentes, los cuales de manera prácticamente invariable siempre manifestaban las dudas sobre la voluntad real del gobierno de abrir un espacio participativo de verdad. "Lo hacen para cubrir el expediente y nada más, ¿verdad?" - era una intervención bastante común y que ponía de manifiesto la desconfianza con la que arrancaba el proceso. Incluso había quien interpretaba el impulso gubernamental del proceso como una trampa, como una farsa en la que, por consiguiente, se negaban a participar.

Sin pretender ser excesivamente optimistas, y derivado de la observación del caso y de las entrevistas, consideramos que el proceso fue capaz de generar cierta confianza y esto fue, probablemente, uno de los éxitos del proceso. No estamos insinuando - ni mucho menos - que el proceso haya generado consensos y acuerdos entre los diferentes actores, los cuales legítimamente defienden sus posiciones, sus intereses y sus visiones dispares. Tampoco estamos afirmando que el gobierno y la administración hayan recuperado un crédito que hoy la sociedad difícilmente les otorga. Consideramos, más modestamente, que todo el mundo pudo mantener sus posiciones pero que, al mismo tiempo, se logró escuchar las de los demás con respeto y con una actitud positiva. Conocer y reconocer a los demás es uno de los objetivos de la deliberación, ya que es el paso previo e imprescindible para poder trabajar juntos.

Los propios participantes, al ser entrevistados, destacaban como uno de los resultados más valorados del proceso deliberativo la oportunidad de establecer nuevas relaciones entre ellos, de haber conocido a otros actores y de haberse enriquecido del intercambio mutuo:

"Hubo mucho feeling entre todos los que estábamos allí [...] La comunicación entre todos mejoró [...] y todo el mundo entendió que tanto los unos como los otros teníamos problemas similares." [Miembro de una entidad ambiental)]

"No hay tantos momentos en los que puedas establecer un diálogo franco, pero cuando éstos aparecen vale la pena." [Industrial]

"A mí me enriqueció mucho, vi que los verdes son muy personas [...] y que nos entendíamos de primera. Sirvió para romper esa frontera que nos imponemos nosotros mismos a veces entre diferentes colectivos, pudimos expresar todas nuestras ideas y pienso que se hizo con mucha claridad por parte de todos." [Agricultor]

Respecto a la relación de los diferentes actores con la administración o, más concretamente, con la ACA, la mayoría de los miembros de la Agencia entrevistados valoraron también la oportunidad de conocer y de darse a conocer;

"Quiero pensar que al menos hay una relación de más confianza." [Miembro de la ACA]

"Había cierto agradecimiento de que fueras allí, que les dedicaras tiempo. Esta relación directa es extremadamente positiva. "[Miembro de la ACA] "Se vio que detrás del ACA había personas.” [Empresario]

No era sencillo conseguir unas relaciones de respeto y de colaboración entre los diferentes actores participantes en el proceso. Lo cierto es que, aunque esto no se logró de forma absoluta, sí que se detectaron síntomas de acercarse a unas relaciones de mayor confianza. La clave radicó en varios factores, entre los que destacaríamos el tiempo dedicado al diálogo, el trabajo de los dinamizadores, el 
papel jugado por los técnicos de la ACA, la claridad de las reglas de juego y la predisposición de los propios participantes:

- La confianza requiere tiempo y éste fue un proceso largo, con múltiples reuniones y muchas horas dedicadas a encontrarse y debatir. La experiencia puede haber sido criticada por sus costes, su lentitud y su excesiva complejidad, pero ha sido indudablemente una oportunidad para construir pacientemente la confianza.

- El papel de los dinamizadores también fue clave a la hora de articular las relaciones y generar confianza entre las partes. Los dinamizadores debían otorgar las palabras, moderar los debates, hacer explícitas las conclusiones, canalizar los conflictos y gestionar los inevitables tropiezos de un debate a menudo difícil y lleno de contradicciones. El esfuerzo de los conductores de los procesos fue imprescindible para generar el clima de confianza que reclama la deliberación.

- De manera similar, el papel de los responsables y los técnicos de la administración fue determinante. Por un lado, su personal directivo estuvo presente en las reuniones informativas, así como en las sesiones de conclusiones y de retorno; dando credibilidad al proceso y respondiendo a los interrogantes y a las propuestas de los participantes. Por otra parte, diversos técnicos de la ACA estuvieron presentes en las 290 sesiones y su papel también resultó, en opinión de los propios participantes, muy positivo.

- Los factores anteriores se enmarcaban en un proceso diseñado a través de unas reglas claras y que respondían a un planteamiento deliberativo explícito. Disponer de estas reglas y ejecutarlas sin concesiones, incluso reconociendo sus límites, evitó sorpresas, generó un terreno de juego conocido y previsible y, finalmente, permitió desarrollar la confianza.

- Finalmente, cabe destacar que las reticencias iniciales de los participantes fueron derivando en una buena predisposición al diálogo y a la colaboración. Los diferentes sectores han demostrado que, más allá de sus intereses legítimos, cuando se les da el espacio y la oportunidad, entienden las posiciones de los demás y son capaces de razonar en términos de interés público.

Si la complejidad de las políticas públicas requiere que, de una u otra manera, los diversos actores se sientan implicados, entonces el proceso deliberativo jugó un papel crucial en la generación de complicidades y confianzas. El proceso se convirtió en un espacio de encuentro donde los diferentes actores se conocían y aprendían a compartir y a trabajar juntos desde el respeto mutuo y la colaboración.

Así pues, la confianza no es sólo un input de los procesos participativos. También es un output y, como tal, debe ser gestionada y producida. Siguiendo las recomendaciones de Child y Faulkner (1998), para generar confianza entre los diferentes actores vinculados a una política pública, deberíamos tomar en consideración tres etapas:

- En primer lugar, la confianza arranca de un cálculo coste-beneficio y, por lo tanto, los actores deben ser conscientes del saldo positivo de esta relación. En términos de nuestro ejemplo, los diferentes actores se incorporaban a una relación (que eventualmente acababa en confianza) sólo si consideraban que el tiempo y los esfuerzos dedicados tenía una compensación su- 
ficiente. En nuestro caso, la oportunidad de incidir en la política, de disponer de información de primera mano y de poder defender los intereses de cada parte fueron razones que compensaban suficientemente a la mayoría de los actores.

- En segundo lugar, la confianza se desarrolla a partir de conocer y reconocer la posición de los otros. Este aspecto, como ya hemos citado, fue generado a partir de un proceso al que se dedicó tiempo y cuidado en las formas. En realidad, algunos de los participantes reconocieron que lo más interesante de este proceso fue precisamente conocer a los otros y, de este modo, superar las desconfianzas iniciales. Este conocer y reconocer al otro no implica acuerdo, pero sí la confianza necesaria para trabajar desde el desacuerdo.

- Finalmente, estos autores nos sugieren que la confianza se consolida a partir de una doble compatibilidad estratégica y cultural; es decir, de compartir objetivos y estilos de trabajo. Este es un escenario al que se debe tender y que, en el caso de la política hídrica, posibilitó ciertas expectativas de continuidad: los consejos de cuencas, otros espacios de encuentro y, en definitiva, la impresión de que, una vez iniciado el camino de la confianza muy frágil, por cierto - los múltiples actores van asumiendo que el trabajo compartido genera mejores resultados que las luchas individuales.

Como hemos venido relatando, el camino hacia la confianza es largo y plagado de obstáculos; un esfuerzo que, sin embargo, se ve compensado cuando se alcanza el destino final. Tal como establecíamos en nuestra hipótesis de trabajo, este destino se describe en términos de política desbloqueada o, expresándolo en términos positivos, en la capacidad de planificar e implementar una política pública compleja en el marco de una sociedad también compleja. Y éste fue, efectivamente, el destino de la experiencia presentada.

De entrada, para mostrar este resultado basta constatar como en Cataluña, a diferencia del resto de cuencas hídricas españolas, el plan de gestión se aprobó en plazo, el 23 de enero de 2010 (decreto 188/2010 que incorporó el programa de medidas del acuerdo GOV/238/2010). En el resto de cuencas hídricas españolas, la política permaneció bloqueada durante un intervalo de entre tres y cinco años. No es el objetivo de este artículo valorar los contenidos de este programa, pero sí mostrar la existencia de una relación entre el proceso deliberativo y la capacidad para aprobar una política pública hídrica.

Un proceso deliberativo que estimuló aquello que en nuestro planteamiento teórico hemos llama la doble confianza: confianza en la capacidad de los actores sociales y económicos de involucrarse en el proceso decisional y confianza en los representantes gubernamentales que tienen la obligación de ejercer la autoridad y adoptar la decisión final. Dos confianzas que se encuentran altamente interrelacionadas y que deben producirse de forma simultánea. Es decir, es la confianza de los gobernantes hacia los gobernados lo que se torna en confianza de los gobernados hacia los gobernantes.

En el resto de cuencas españolas se mantuvo la lógica de la doble desconfianza y, consecuentemente, el bloqueo de la política. La desconfianza hacia los ciudadanos inhibió a las autoridades hídricas en la realización de un auténtico proceso deliberativo y, de esta forma, no sólo no incorporaron sus aportaciones, sino que se ganaron la desconfianza de unos actores que, en última instancia, han sido capaces de bloquear el despliegue de una política. De 
una política compleja que no era capaz de incorporar la complejidad en el proceso decisional.

Podemos concluir este punto valorando los resultados del proceso deliberativo en términos del tipo de decisión de política pública finalmente adoptada. Para ello nos apoyaremos en las cuatro características que, según Gutmann y Thompson (2004), provoca la deliberación en las decisiones finales. Como podrá comprobarse enseguida, estos autores no se refieren a los contenidos sectoriales de cualquier decisión (es decir, a aspectos hídricos, sociales o escolares de unas políticas determinadas) sino a atributos de la propia decisión. Parten de preguntarse sobre para qué dedicar tanto tiempo y esfuerzo a tomar una decisión siguiendo la lógica deliberativa y nos proponen los cuatro argumentos que podemos trasladar a nuestro caso de estudio:

i. En primer lugar, Gutmann y Thompson (2004) consideran que, en un contexto de "recursos limitados", un proceso deliberativo permite dotar a las decisiones de "legitimidad". No se trata de un aspecto menor, pues aquí radica quizá la principal razón del bloqueo de las políticas públicas. Sin explicar la iniciativa política, sin escuchar a los múltiples actores y sin establecer un cauce de diálogo con ellos se cultiva la desconfianza y no se alcanza la legitimidad necesaria para adoptar decisiones complejas. En sociedades más simples esta legitimidad podía adquirirse invocando a la posición que ocupaba el decisor (legitimidad formal) o a las bases técnicas que justificaban su decisión (legitimidad tecnocrática), pero en nuestras sociedades actuales se reclama una tercera fuente de legitimidad: la legitimidad democrática, aquella que se deriva de un proceso deliberativo que, a su vez, se basa en la confianza en los gobernados.

ii. En segundo lugar, dado que, usando las palabras de Gutmann y Thompson (2004), la "generosidad es limitada" (o, si se prefiere ser menos eufemístico, que somos egoístas), el proceso deliberativo sirve para favorecer la aparición del "interés público". En este punto queremos destacar la importancia de un proceso que, además de escuchar a los gobernados, confía también en los representantes que han de realizar una tarea crucial de síntesis de las posiciones legítimamente diversas de los múltiples y diversos actores involucrados en la política pública. El "interés público", por lo tanto, se entiende no únicamente como la agregación de intereses particulares sino como una construcción colectiva que reclama confiar en las tareas de intermediación de los gobernantes. Una confianza en la representación que Innerarity (2015, p.259) expresa en los siguientes términos:

“[...] una democracia no es un régimen en el que se hace lo que todos queremos sino un régimen en el que las decisiones individuales tienen alguna influencia en la decisión colectiva final".

iii. En tercer lugar, en un entorno de alta complejidad donde "existen posiciones legítimamente incompatibles entre ellas" (por ejemplo, entre la apuesta por la conservación y el crecimiento), un proceso deliberativo como el que defienden Gutmann y Thompson (2004) debería servir para generar "respeto mutuo" o, si se prefiere, para mantener la posibilidad de trabajar juntos desde la discrepancia. Este es un tema crucial en una política pública tan poliédrica y polémica como la hídrica. Una política donde el desbloqueo no pasa por un acuerdo imposible sino por un desacuerdo respetuoso con las posiciones de los demás. Como ya hemos comentado, sólo cuando trabajamos las condiciones de la doble confianza es posible dar cauce esta situación. 
iv. Finalmente, estos autores asumen que la complejidad de las políticas públicas implica la necesidad de tomar decisiones en contextos donde "el conocimiento es limitado". En estos contextos, la deliberación actúa como fuente de aprendizaje e innovación. Recuperando aquella vieja idea de Aristóteles según la cual muchos siempre tomas decisiones más sabias que uno (por sabio que sea este uno), Gutmann y Thompson (2004) nos proponen que confiemos en los conocimientos dispersos de los actores sociales. Únicamente contando con estos conocimientos podremos tomar las decisiones apropiadas a realidades crecientemente complejas.

\section{Conclusiones}

La desconfianza, tal como argumenta Rosanvallon (2007), es un ingrediente básico para el buen funcionamiento de la democracia. Esta afirmación se enmarca en una teoría normativa de la democracia que institucionaliza la desconfianza como una forma de garantizar el poder de los gobernados sobre los gobernantes. Los gobernantes pueden tomar decisiones, pero siempre bajo la atenta lupa de los ciudadanos y la permanente amenaza de ser sustituidos en las próximas elecciones. La desconfianza es el pegamento que mantiene unidas las partes esenciales de los regímenes democráticos.

Sin embargo, como ya hemos apuntado anteriormente y como bien argumenta Innerarity (2015), nuestras sociedades tienden a mostrar una desconfianza patológica hacia la política. Una desconfianza exacerbada que se traduce, primero, en un intenso descrédito (Mattei 2005) y, más tarde, en lo que la literatura etiqueto como el "policy failure" y que nosotros hemos reinterpretado como el bloqueo de las políticas públicas.

Así pues, cuando abordamos la democracia como una forma específica de tomar decisiones (meso-teoría), una versión excesivamente acentuada de la desconfianza democrática puede resultar paralizante. Incluso más, la toma de decisiones en contextos de elevada complejidad puede reclamar de ciertas dosis de confianza tanto hacia las capacidades cognitivas de los gobernados como hacia la responsabilidad decisora de los gobernantes. Si combinamos unos gobernantes incapaces de confiar en los conocimientos de los ciudadanos y unos ciudadanos incapaces de confiar en la capacidad de los gobernantes para tomar decisiones, el resultado es el bloqueo de las políticas públicas.

El reto de nuestras sociedades, por lo tanto, consiste en mantener un régimen político basado en la desconfianza democrática y, simultáneamente, compensarla con una confianza relativa tanto hacia la ciudadanía como hacia los representantes políticos. La clave, desde nuestro punto de vista, tal como hemos ejemplarizado con el caso hídrico, está en la democratización de las políticas públicas. Una democratización que implica deliberación y autoridad o, si se prefiere, deliberación por parte de unos ciudadanos en los que confiamos y confianza en la capacidad de nuestros representantes para tomar decisiones dotadas de autoridad (Brugué 2014).

No va a ser fácil confiar ni en unos ni en otros, pero quizá podamos avanzar si somos capaces de mostrar la relación entre la doble confianza y el éxito de determinadas políticas públicas. Este ha sido el objetivo de nuestro artículo. No podemos extraer conclusiones definitivas de un único estudio de caso, pero el análisis del proceso deliberativo que acompañó la política de agua -que combinaba la confianza en la ciudadanía con el reconocimiento de la autoridad de los gobernantes a la hora de tomar la decisión final- apunta en la dirección de nuestra hipótesis y abre la puerta a una línea de trabajo que relaciona tres conceptos claves: confianza, democracia y políticas públicas. Un triángulo con- 
ceptual que puede ayudarnos a desbloquear la parálisis política que atenaza a nuestras sociedades.

Además, al trasladar este triángulo conceptual a la contrastación empírica hemos podido reflexionar sobre las condiciones que permiten a los procesos deliberativos generar situaciones de confianza. En este sentido, a modo de resumen, nos hemos referido a aspectos como:

i. La diversidad de actores. Una diversidad que garantiza la diversidad de intereses y permite que la confianza se derive de la interacción entre diferentes, con los otros (Lechner 2000).

ii. La existencia de reglas y procesos claramente definidos y vinculados a decisiones finales que se tomaran con ejercicio de autoridad. Aquí, más que las razones morales, la confianza se deriva de cálculos e incentivos (Herreros 2002; Rothstein 2000).

iii. Las actitudes de respeto son una variable fundamental en la generación de confianza. Se trata de un aspecto que nos acerca al mundo de las emociones, pero que también podemos trabajar desde los liderazgos y las dinámicas y los tiempos deliberativos.

En definitiva, la estrategia para construir la confianza debe combinar ingredientes diversos y que provienen de tradiciones teóricas también dispares (Güemes 2017). Se nos abre, pues, un campo de investigación amplio en el que todavía quedan muchos interrogantes por resolver, por ejemplo, en relación a la estabilidad y la durabilidad de una confianza que, como hemos visto en el estudio de caso, tanto cuesta de alcanzar. O si, efectivamente, las dinámicas democráticas hoy imperantes - bajo el lema del No nos representan - son una amenaza a nuestra hipótesis o una razón más para avanzar en la dirección de recuperar la doble confianza. Esperamos, en futuras investigaciones, poder contribuir a responder a estos y otros interrogantes que nos parecen cruciales tanto para nuestra disciplina como para la gobernabilidad de las sociedades actuales.

${ }^{\text {I }}$ Quim Brugué i Torruella (q.brugue@udg.edu) es Doctor en Ciencia Política y de la Administración por la Universidad Autónoma de Barcelona (España) y profesor del Departamento de Pedagogía de la Universidad de Girona. Vinculación Institucional: Departamento de Pedagogía, UdG, Girona, CAT, España.

II Jordi Feu Gelis (jordi.feu@udg.edu) es Doctor en Pedagogía por la Universidad de Girona (España) y profesor del Departamento de Pedagogía de la misma Universidad. Vinculación Institucional: Departamento de Pedagogía, UdG, Girona, CAT, España.

III Cecilia Güemes (cguemes@clio.uc3m.es) es Doctora en Ciencias Políticas por la Universidad Complutense de Madrid (España) y profesora asociada en el Departamento de Ciencias Sociales de la Universidad Carlos III de Madrid (España). Vinculación Institucional: Departamento de Ciencias Sociales, UC3M, Madrid, MAD, España.

\section{Referencias}

Agranoff, R. \& McGuire, M., 2003. Collaborative Public Management. Washington, DC: Georgetown University Press. Arrow, K.J., 1974. The Limits of Organizations. New York: Norton Press.

Barber, B., 1984. Democracia Fuerte. Granada: Alhambra.

Behn, R.D., 2001. Rethinking Democratic Accountability. Washington, DC: Brookings Institution Press.

Bovens, M. \& Hart, P., 1998. Understanding Policy Fiascoes. New Brunswick: Transaction Press.

Boyden, M., 2008. Public Participation and the Water Framework Directiva: Overview, Interpretations and Recomendations. Bantry: StreamScapes Project.

Brugué, Q., 2012. És la Política, Idiotes. Girona: Accent.

Brugué, Q., 2014. Políticas Públicas: entre la deliberación y el ejercicio de autoridad. Cuadernos de Gobierno y Administración Pública, 1(1), pp.37-55. DOI: 10.5209/rev_cgap.2014.v1.n1.45157

Brugué, Q. et al., 2012. Política d'Aigua amb Dialeg Social. L’Aplicació de la DMA a Catalunya. Barcelona: IGOP-UAB. Dunn, J., 1993. Trust. In R. Goodin \& P. Pettit, eds. A Companion to Contemporary Political Philosophy. Oxford: Blackwell. 
Elster, J., ed., 1998. Deliberative Democracy. Cambridge: Cambridge University Press.

Espluga, J.; Ballester, A.; Hemández-Mora, N. \& Subirats, J., 2011. Participación Pública e Inercia Institucional In la Gestión del Agua In España. Revista Española de Investigaciones Sociológicas, 134, pp.3-26. DOI: 10.5477/cis/reis.134.3

Child, J. \& Faulkner, D., 1998. Strategies of Co-operation. Oxford: Oxford University Press.

Crossman, R., 1977. Biografia del Estado Moderno. Madrid: Fondo de Cultura Económica.

Finley, M.I., 1992. Los Griegos de la Antigüedad. Colombia: Labor.

Fiskin, J.S., 2011. When the People Speak. Oxford: Oxford University Press.

Fukuyama, F., 1996. Trust: The Social Virtues and the Creation of Prosperity. New York: Free Press.

Gambwetta, D., ed., 1988. Trust: Making and Breaking Cooperative Relations. Oxford: Blackwell.

García Gual, C., 1995. La Grecia Antigua. In F. Vallespín, ed. Historia de la Teoría Política. Madrid: Alianza,

Geyer, R. \& Rihani, S., 2010. Complexity and Public Policy. London: Routledge.

Güemes, C., 2016. Trátame suavemente. Confianza Social In América Latina, con la lupa In Argentina. San José de Costa Rica: Flacso.

Güemes, C. \& Brugué, Q., 2017. Confianza y Gobierno Abierto In América Latina. In A. Nasser; A. Ramírez-Alujas \& D. Rosales, eds. Desde Gobierno Abierto al Estado Abierto In América Latina y el Caribe: hacia una nueva arquitectura para enfrentar los desafíos de la agenda 2013 para el Desarrollo Sostenible. Santiago de Chile: CEPAL.

Gutmann, A. \& Thompson, D., 2004. Why Deliberative Democracy. Princeton: Princeton University Press.

Hajer, M. \& Wagenaar, H., 2003. Deliberative Policy Analysis: Understanding Governance in the Network Society. Cambridge: Cambridge University Press.

Hardin, R., 2002. Trust and Trustworthiness. New York: Russell Sage Foundation.

Herreros, F., 2002. Republicanismo, Capital Social y Democracia. Revista de Estudios Políticos, 117, pp.293-312.

Horgan, J., 1996. The End of Sciences: Facing the Limits of Knowledge in the Twilinght of the Scientific Age. New York: Broadway Books.

Ibarra, P.; Martí, S. \& Gomà, R., eds., 2002. Creadores de Democracia Radical. Barcelona: Icaria.

Innerarity, D., 2015. La Política In Tiempos de Indignación. Barcelona: Galaxia Gutemberg.

Jaeger, W., 1962. Paidea. Los Ideales de la Cultura Griega. México: Fondo de Cultura Económica.

Landau, M., 2009. La conflictiva relación entre participación institucionalizada y confianza: el caso de Buenos Aires. Perfiles latinoamericanos, 17(34), pp.111-124.

Lathrop, M. \& Ruma, L., 2010. Open Government: Collaboration, Transparency and Participation in Practice. Sebastopol: O'Reilly Books.

Lechner, N., 2000. Desafíos de un Desarrollo Humano: Individualización y Capital Social. Instituciones y Desarrollo, 7 , pp.7-34.

Levi, M. \& Stoker, L., 2000. Political Trust and Trustworthiness. Anual Review of Political Science, 3(1), pp.475-508. DOI: 10.1146/annurev.polisci.3.1.475

Lewis, D. \& Weigert, A., 1985. Trust as a Social Reality. Social Force, 63(4), pp.967-985. DOI: 10.1093/sf/63.4.967

Luhmann, N., 1996. Confianza. Barcelona: Anthropos.

Madison, J.; Hamilton, A. \& Hay, J., 2009. El Federalista. Colección Clásicos del Federalismo. Barcelona: Institut d’Estudis Autonòmics, Generalitat de Catalunya.

Mattei, D., 2005. Political Mistrust and the Discrediting of Politicians. Boston: Brill.

Möllering, G., 2006. Trust Beyond Risk: The Leap of Faith. Oxford: Elsevier.

Montero, J.R.; Zmerli, S. \& Newton, K., 2008. Confianza Social, Confianza Política y Satisfacción con la Democracia. REIS, 122, pp.11-54. DOI: $10.2307 / 40184879$

Osborne, T. \& Gaebler, J., 1998. La Reinvención del Gobierno. Barcelona: Paidós.

Ostrom, E., 1990. Governing the Commons. The Evolution of Institutions for Collective Action. Cambridge: Cambridge University Press.

Parès, M.; Ballester, A.; Espluga, J. \& Brugué, Q., 2014. Gobernanza Deliberativa In la Gestión de Cuencas Hidrográficas: Analizando las Consecuencias de la DMA In Cataluña. Investigaciones Geográficas, 61, pp.113-127. DOI: 10.14198/ingeo2014.61.08

Parès, M.; Espluga, J.; Miralles, J. \& Ballester, A., 2015. The Strenghts and Weaknesses of Deliberation on River Basin Management Planning: Analyzing the Water Framework Directive Implementation in Catalonia (Spain). Enviromental Policy and Governance, 25(2), pp.97-110. DOI: 10.1002/eet.1662

Peters,T.J. \& Waterman, R.H., 1982. In Search of Excellence. New York: Harper \& Row.

Pollit, J.; Bouckaert, G. \& Löffler, E., 2006. Making Quality Sustainable: Co-design, Co-decide, Co-produce and Co-evaluate. Helsinky: Ministery of Finance.

Putnam, R., 1993. Making Democracy Work. Civic Traditions in Modern Italy. Princeton: Princeton University Press.

Rabelo, D.C.; Espluga, J.; Teixeira, E.C. \& Brugué, Q., 2014. Citizen Participation in Water Management Plans in the Doce River Basin, Brazil ans Catalonia, Sapin. Water Policy, 16(2), pp.205-221. DOI: 10.2166/wp.2013.077

Requejo, F., 1990. Las Democracias: Democracia Antigua, Democracia Liberal y Estado de Bienestar. Barcelona: Ariel.

Ritter, H. \& Webber, M., 1973. Dilemmas in General Theory of Planning. Policy Sciences, 4(2), pp.155-169. DOI: 10.5040/9781474282932.0015

Rosanvallon, P., 2007. La Contrademocracia. La Política In la Era de la Desconfianza. Buenos Aires: Manantial. 
Rothstein, B., 2000. Trust, Social Dilemmas, and the Strategic Construction of Collective Memories. Journal of Theoretical Politics, 12(4), pp.477-501. DOI: 10.1177/0951692800012004007

Sartori, G., 1987. Teorías de la Democracia. Buenos Aires: Alianza.

Scott, J., 1998. Seeing Like a State. New Haven: Yale University Press.

Stone, D., 2002. Policy Paradox. The Art of Political Decision Making. New York: Norton \& Company.

Sztompka, P., 2000. Trust: A Sociological Theory. Port Chester, NY: Cambridge University Press.

Tilly, C., 2005. Trust and Rule. Cambridge: Cambridge University Press.

Uslaner, E.M., 2002. The Moral Foundations of Trust. Cambridge: Cambridge University Press.

Van del Walle, S. \& Lahat, L., 2012. Do Public Officials Trust Citizens? In IIAS Study Group on Trust and Public Attitudes Workshop. Seoul.

Videira, N.; Van den Belt, M.; Antunes, P.; Santos, R. \& Gamito, S., 2003. Public Participation in Integrated River Basin Governance. Brussels: FFCT/ECOMAN.

Wagenaar, H., 2007. Governance, Complexity and Democratic Participation. The American Review of Public Administration, 37(1), pp.17-50.

Warren, M.K., ed., 1999. Democracy and Trust. Cambridge: Cambridge University Press.

Wences, I. \& Güemes, C., 2016. Democracia republicana y confianza In América latina: la esperanza que no llega, que no alcanza. Andamios, 13(30), pp.13-37. DOI: 10.29092/uacm.v13i30.1

Wildavsky, A., 1979. Speaking Truth to Power. The Art and Craft of Policy Analysis. New York: Little Brown.

Wilson, E.O., 1998. Consilience: the Unity of Knowledge. New York: Vintage Books.

Yang, K., 2005. Public Administrators' Trust in Citizens: A Missing Link in Citizen Involvement Efforts. Public Administration Review, 65(3), pp.273-285. DOI: 10.1111/j.1540-6210.2005.00453.x

Yin, R.K., 1984. Case Study Research: Design and Methods. Beverly Hills: Sage Publications.

\section{Outras fontes}

ACA. Agència Catalana de l'Aigua, 2006. La Directiva Marc de l'Aigua: La Nova Política de l'Aigua per a una Nova Cultura de l'Aigua. Barcelona: Agència Catalana de l'Aigua.

ACA. Agència Catalana de l'Aigua, 2010. Memòria dels Processos Participatius de l'Aigua. Directiva Marc de l'Aigua 2006-2010. Barcelona: Agència Catalana de l'Aigua.

Democratic trust and the process of formulating public policies: the case of the water policy of Catalonia

ABSTRACT Introduction: Under the premise that democratic political and administrative systems work through certain trust and distrust assignments, this paper aims to focus on a reality where double distrust reigns between citizens and the public administration. It tries to create an alternative, which uses citizen participation and deliberation between citizen and public administration to bring more democracy to public policies without renouncing the exercise of authority necessary to adopt policies. Methods: After a few theoretical and analytical sections, the case of democratization Catalonias water policy in the context of the Spain and Europe normative is analyzed. We highlight the results achieved and the keys to success in unlocking the distrust and formulating a public policy. Results: The hypothesis and main finding of the research are the conditions that generate trust in the deliberative process, which are: diversity of actors (interaction with the other), rules and processes clearly defined and linked to final decisions that will be taken with the exercise of authority, and attitudes of respect. Discussion: The important thing of the paper is to offer keys derived from and empirical analysis of a case to thing about how to build the double trust and to encourage the deliberative process that our democracy need. In his line, the work advances the construction of an alternative by appealing to citizen participation and deliberation among citizen and public administrations, and generates a democratization of public decisions without renouncing the essential exercise of authority that implies approving any public policy.

KEYWORDS: public policies; trust; deliberation; water policy; Catalonia.

This is an Open Access article distributed under the terms of the Creative Commons Attribution Non-Commercial License which permits unrestricted non-commercial use, distribution, and reproduction in any medium provided the original work is properly cited. 